\title{
Effect of Lamium Album on Mitochondrial Oxidative Stress in Diabetic Rats
}

\author{
Korosh Khanaki ${ }^{1}$, Mahmood Abedinzade ${ }^{2}$, Rouhollah Gazor ${ }^{3,4}$, Mohammadreza Norasfard ${ }^{5}$, Reza Jafari-Shakib ${ }^{4,6 *}$ \\ 1 Medical Biotechnology Research Center, Department of Clinical Biochemistry, Faculty of Paramedicine, Guilan University of Medical \\ Sciences, Rasht, Iran. \\ ${ }^{2}$ Medical Biotechnology Research Center, Department of Physiology, Faculty of Paramedicine, Guilan University of Medical Sciences, Rasht, \\ Iran. \\ ${ }^{3}$ Department of Anatomical Sciences, Faculty of Medicine, Guilan University of Medical Sciences, Rasht, Iran. \\ ${ }^{4}$ Cellular and Molecular Research Center, Faculty of Medicine, Guilan University of Medical Sciences, Rasht, Iran. \\ ${ }^{5}$ Department of Physiology, Faculty of Medicine, Guilan University of Medical Sciences, Rasht, Iran. \\ ${ }^{6}$ Department of Immunology, Faculty of Medicine, Guilan University of Medical Sciences, Rasht, Iran.
}

\section{Received: 8 Feb 2017}

Revised : 1 Mar 2017

Accepted: 17 Mar 2017

Corresponding Author:

Reza Jafari-Shakib

Cellular and Molecular Research Center, Faculty of Medicine, Guilan University of Medical Sciences, Rasht, Iran.

Phone: +98-1333690921

E-mail: shakib@gums.ac.ir

\begin{abstract}
Background: Diabetes mellitus (DM) is characterized by the presence of hyperglycemia. It has been documented that oxidative stress and reactive oxygen species (ROS) production have a key role in the pathogenesis of diabetes and its complications. Neutrophils as a part of immune system produce ROS, neutrophils function might be altered in diabetes. Lamium album is known to have antioxidant, and free radical scavenging actions. The aim of the present study was to evaluate the potential effect of $L$. album on mitochondrial ROS production from circulating neutrophils in diabetic rats.

Materials and Methods: Twenty-one male Wistar rats were randomly divided into three groups: normal control rats receiving daily saline; diabetic control rats receiving daily saline; and diabetic rats treated daily with hydroalcoholic extract of L. album $(100 \mathrm{mg} / \mathrm{kg})$ for 28 days. On the $28^{\text {th }}$ day of treatment, whole blood samples were obtained and mitochondrial ROS of neutrophils were measured by dihydrorhodamine (DHR) flow cytometric method. Also, fasting blood sugar (FBS) was measured.

Results: Mitochondrial ROS didn't show any significant differences among diabetic rats treated with $L$. album extract, diabetic control rats, and normal control rats $(\mathrm{P}=0.8)$. Serum glucose in diabetic control was significantly higher than normal control rats $(\mathrm{P}=0.0001)$. However, $L$. album caused a remarkable decrease in serum glucose of diabetic rats $(\mathrm{P}=0.03)$.

Conclusion: According to the present findings, it seems that $L$. album at a dose of $100 \mathrm{mg} / \mathrm{kg}$ could not decrease mitochondrial ROS production from neutrophils in diabetic rats. Further studies considering higher concentrations of $L$ album are appreciated to evaluate its impact on the production of mitochondrial ROS along with extracellular ROS in diabetes condition.
\end{abstract}

Keywords: Diabetes mellitus (DM), Lamium album, Reactive oxygen species (ROS), Dihydrorhodamine (DHR) test

\section{Introduction}

Diabetes mellitus (DM) is the most common endocrine disorder characterized by the presence of hyperglycemia. DM is the result of insulin deficiency, insulin resistance, or both and leads to major problems such as abnormalities in carbohydrate, lipid and protein metabolism. These abnormalities could damage to the main organs including liver, kidney and pancreas $(1,2)$.

The number of patients with diabetes is expected to increase to 366 million by the year 2030 (3). Since the incidence rate of this complex disease worldwide is rising considerably (4), there is still an urgent need 
for effective therapeutic interventions with low side effects and low associated costs.

$\mathrm{DM}$ is a multifactorial disorder (5); it has been suggested that increased oxidative stress plays an important role in the pathogenesis of diabetes (6) as shown in both experimental animals and subjects with diabetes $(7,8)$. It is well documented that oxidative stress is the result of an imbalance between free radical production and antioxidant defense system. Hyperglycemia results in enhanced formation of free radicals such as reactive oxygen species (ROS), and many studies have suggested that diabetes complications might be the result of increased formation of free radicals and ROS production (9-13). It is well documented that the main source of ROS in most cells are mitochondria (14). Neutrophils as a part of immune system produce considerably more ROS than other cells, neutrophils function might be altered in diabetes $(15,16)$.

Since some studies have shown the beneficial antioxidant activity of some plant extracts like Curcumin (17) and Genistein (18) in diabetes, finding other plant extracts with more powerful activity is appreciated.

Lamium album or non-stinging nettle, is known to present several beneficial properties containing antiproliferative, anti-inflammatory, antioxidant, and free radical scavenging actions (19-22).

Information about antioxidant efficiency of $L$. album on mitochondrial ROS production is missing, so the present study was conducted to evaluate the potential effect of $L$. album on mitochondrial ROS production from circulating neutrophils in diabetic rats.

\section{Materials and methods \\ Animals}

During this experimental study, adult male Wistar rats $(250-300 \mathrm{~g})$ were used. The selected animals were housed under normal laboratory conditions $(12 \mathrm{~h}$ light: $12 \mathrm{~h}$ dark photoperiod; at $22-26{ }^{\circ} \mathrm{C}$ ) with free access to their appropriate diet and water. All procedures were performed in accordance with the internationally accepted principles for laboratory animal care and use as found in the US guidelines (NIH publication \#85-23, revised in 1985). This study was approved by the research committee at Guilan University of Medical Sciences (Rasht, Iran) (No 93112004)

\section{Diabetes induction}

The rats were fasted overnight and treated with a single intraperitoneal (IP) injection of STZ (50 mg/kg body weight freshly prepared in sodium citrate buffer) (23) (Sigma- Aldrich Diagnostic Ltd). Normal rats received the same volume of sodium citrate buffer. Diabetes was confirmed by measuring blood glucose by glucometer (Accu chek, Roche, Germany) three days after injection. Rats with fasting blood glucose more than $300 \mathrm{mg} / \mathrm{dl}$ were accepted as diabetic rats (23).

\section{Plant material and extraction Plant material}

Aerial part of L. album was collected from suburbs of Rasht city (Guilan province) in spring 2016 and the species were authenticated at the herbarium unit of Pharmacognosy Department, Pharmacy Faculty (Guilan University of Medical Sciences ; Herbarium number: 202HGUM).

\section{Plant extraction and chemical assessment}

The aerial part of L. album was dried in the shade. Preparation of the extract was done as previously described (24). The total phenolic content of the nettle extract was determined using the FolinCiocalteu reagent (25). Gallic acid was used as standard and the result was expressed as mg gallic acid (GAL)/gr plant extract; total phenolic content of L. album was $0.61(\mathrm{mg} \mathrm{GAL} / \mathrm{gr})$.

Total flavonoid content was determined using aluminium chloride ( $\mathrm{AlCl} 3$ ) (26). Quercetin was used as a standard and the result was expressed as $\mathrm{mg}$ quercetin $(\mathrm{QE}) / \mathrm{gr}$ plant extract; Total flavonoid content of L. album extract was 2.10 (mgQE/gr)

\section{Study Design}

All rats were randomly divided into three groups, each group containing seven rats $(27,28)$ as follows:

Group I: normal control rats receiving daily saline; Group 2: diabetic control rats receiving daily saline; Group 3: Diabetic rats treated daily with $100 \mathrm{mg} / \mathrm{kg}$ of hydroalcoholic extract of L. album.

Treatment began three days after diabetes induction by IP injection and all the rats were maintained for 28 days on their respective treatments (24).
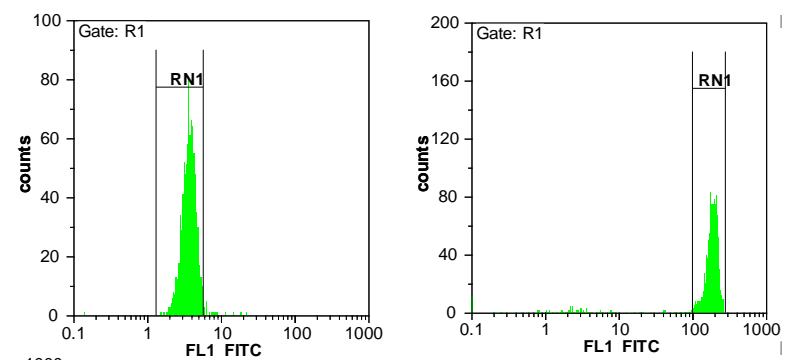

Figure 1. Unstimulated (left panel) and PMA-stimulated sample (right panel).

On the $28^{\text {th }}$ day of treatment, whole blood samples were obtained and used for dihydrorhodamine (DHR) flow cytometric test by Partec flow cytometry as 
previously described (29). Briefly, DHR (a nonfluorescent compound) enters the cells and is changed to rhodamine (highly fluorescent) as a result of the action of mitochondrial ROS. We performed the test in whole blood and measured the test in neutrophils by flow cytometry gating. Stimulation index was calculated by division of mean channel fluoroscence between phorbol myristate acetate (PMA)-stimulated to unstimulated samples (Figure 1). Also, fasting blood sugar (FBS) was measured. DHR, catalase and PMA were purchased from Sigma-Aldrich.

\section{Statistical Analysis}

Data are presented as mean \pm SD or SEM as appropriate. Inter-group comparisons were performed using the one-way analysis of variance (ANOVA). For all tests, $P<0.05$ was considered statistically significant. Data were analyzed using SPSS software version 16.

\section{Ethics Statements}

All authors hereby declare that all experiments have been performed and approved by the appropriate ethics committee and have therefore been performed in accordance with the ethical standards laid down in the 1964 Declaration of Helsinki.

\section{Results}

Effect of L. album on mitochondrial ROS

Mitochondrial ROS didn't show any significant differences among diabetic rats treated with $L$. album extract, diabetic control rats, and normal control rats $(\mathrm{P}=0.8)$ (Table 1).

Table 1. Effect of Lamium album on mitochondrial oxidative stress and serum glucose in streptozotocin-induced diabetic rats on the 28th day of treatment.

\begin{tabular}{llll}
\hline Groups & Stimulation Index $^{\mathbf{a}}$ & Serum glucose $(\mathbf{m g} / \mathbf{d l})^{\mathbf{b}}$ & ${\text { Weight }(\mathbf{g})^{\mathbf{a}}}^{\text {Normal control }}$ \\
Diabetic control & $48.57 \pm 9.34$ & $107.71 \pm 7.80$ & $275.14 \pm 24.81$ \\
Diabetic+ Lamium & $48.04 \pm 9.87$ & $466.50 \pm 41.14^{\mathrm{c}}$ & $212.29 \pm 37.05^{\mathrm{c}}$ \\
\hline
\end{tabular}

${ }^{a}$ Values are given mean \pm SD. ${ }^{b}$ Values are given mean \pm SEM.

${ }^{\mathrm{c}} \mathrm{P}<0.01$ by comparison with normal control rats.

${ }^{\mathrm{d}} \mathrm{P}<0.05$ by comparison with diabetic rats.

Effect of L. album on serum glucose and weight On day 28, serum glucose of diabetic control rats was significantly higher than that of normal control rats $(\mathrm{P}=0.0001)$. However, $L$. album caused a remarkable decrease in serum level of glucose in diabetic rats $(\mathrm{P}=0.03) \quad$ (Table 1). Also, weight decreased significantly in the diabetic control rats $(\mathrm{P}=0.003)$ and the diabetic rats treated with $L$. album $(\mathrm{P}=0.001)$ (Table 1).

\section{Discussion}

The main finding of the present study was that mitochondrial ROS from neutrophils were not statistically significant among diabetic rats exposed to $L$. album (at dose of $100 \mathrm{mg} / \mathrm{kg}$ ), diabetic control and normal control rats.

Our finding was partially in agreement with that of the study conducted by Marin et al. (15) in which Astaxanthin (ASTA) at one dose was not effective in decreasing intracellular ROS production from neutrophils in alloxan-induced diabetic rats. It should be noted that in our study only one dose of $L$. album extract was used; it is likely that using higher concentrations of the extract could be more useful than the present therapeutic procedure.
In contrast to the present study, Rossoni-Júnior et al. (16) showed that ROS production in peripheral neutrophil was significantly lower in diabetic rats treated with Annatto extract compared with nondiabetic and diabetic rats. It was concluded that Annatto extract might be beneficial at controlling ROS production possibly by modulation of NADPH oxidase activity or gene expression. Guerra et al. (30) found that diabetic rats receiving $2 \%$ acai (as diet supplementation) had significantly lower production of ROS in neutrophils. They concluded that the reducing effect of acai on the production of ROS might be commonly due to its polyphenols. It has been demonstrated that polyphenols are able to directly deactivate pre-oxidant reactive species and indirectly activate the gene transcription of antioxidant enzymes (31). In Rossoni-Júnior et al. (16) and Guerra et al. (30) studies, ROS production was quantified by chemiluminescence method; it is demonstrated that this assay mainly determines $\mathrm{O} 2 \cdot$ (32). In the present study, the intervention of $L$. album in diabetic rats was assessed and it didn't cause decrease in ROS compared with diabetic control rats. Mitochondrial ROS production was determined using DHR flow cytometric test. Through 
flow cytometric technique, prominently intracellular $\mathrm{H} 2 \mathrm{O} 2$ production was assessed $(33,34)$. Although, blood samples were not subjected to isolation of polymorphonuclear leukocytes (PMNs) but the test was measured in PMNs by flow cytometry gating.

In the present study, mitochondrial ROS production from neutrophils had no significant difference in diabetic rats as compared to normal control rats. Our finding was partly in line with that of Nakanishi et al. study (34) in which baseline level of mitochondrial ROS in diabetic patients was not significantly different from healthy subjects. It has been suggested that hyperglycemia condition could induce mitochondrial ROS production by activation of protein kinase C (PKC) $(35,36)$, however, PKC might not always be activated in diabetic patients (34).

In the present study, phytochemical analysis of this plant extract has determined polyphenols and flavonoids (20). The hypoglycemic effect of $L$. album could be in part attributed to its polyphenol compounds (37).

Our study had some limitations: 1) we didn't measure plasma catecholamines and cortisol, since these hormones could affect neutrophil distribution (38, 39). 2) Using DHR dye, the degree of mitochondrial ROS might be affected by the unsolicited alterations in the mitochondrial membrane potential (34); therefore, an additional probe is needed to confirm the results (33).

Overall, according to our findings, it seems that $L$. album at a dose of $100 \mathrm{mg} / \mathrm{kg}$ could not decrease mitochondrial ROS production from neutrophils in diabetic rats. Clearly, in view of the limits of our study, the interpretation of $L$. album influence appears to be problematic. Therefore, more studies using higher concentrations of $L$. album are appreciated to evaluate its impact on the production of mitochondrial ROS along with extracellular ROS in diabetes condition.

\section{Acknowledgements}

This study was supported by grants from the Research Deputy of Guilan University of Medical Sciences (grant number 93112004). We also gratefully acknowledge Mr. Morovvati and Mr. Alavi (Faculty of Medicine, Guilan University of Medical Sciences, Rasht, Iran) for technical assistance.

\section{Authors' Contributions}

K.K and RJS designed the study, wrote the protocol, performed the interpretation of data and wrote the first draft of the manuscript. MA, RG, and MN managed the acquisition of data. K.K and RJS performed critical revision of the manuscript and managed the literature searches. MA, RJS and RG performed analysis and administrative, technical and material support. All authors read and approved the final manuscript.

\section{Conflicts of Interest}

All authors state that there is no conflict of interest in the present study.

\section{References}

1. Maitra A, Abbas AK. The endocrine system. Robbins and Cotran Pathologic basis of disease. Philadelphia: ElsevierSaunders. 2005; 8:1107-26.

2. Robertson RP. Chronic oxidative stress as a central mechanism for glucose toxicity in pancreatic islet beta cells in diabetes. $\mathrm{J}$ Biol Chem. 2004; 279(41):42351-4. PMID: 15258147

3. Wild S, Roglic G, Green A, Sicree R, King H. Global prevalence of diabetes: estimates for the year 2000 and projections for 2030. Diabetes care. 2004; 27(5):1047-53. PMID: 15111519

4. Yach D, Hawkes C, Gould CL, Hofman KJ. The global burden of chronic diseases: overcoming impediments to prevention and control. JAMA. 2004; 291(21):2616-22. PMID: 15173153

5. van Belle TL, Coppieters KT, von Herrath MG. Type 1 diabetes: etiology, immunology, and therapeutic strategies. Physiol Rev. 2011; 91(1):79-118. PMID: 21248163

6. Kaneto H, Katakami N, Kawamori D, Miyatsuka T, Sakamoto $\mathrm{K}$, Matsuoka TA, et al. Involvement of oxidative stress in the pathogenesis of diabetes. Antioxid Redox Signal. 2007; 9(3):35566. PMID: 17184181

7. Kedziora-Kornatowska K, Szewczyk-Golec K, Kozakiewicz M, Pawluk H, Czuczejko J, Kornatowski T, et al. Melatonin improves oxidative stress parameters measured in the blood of elderly type 2 diabetic patients. J Pineal Res. 2009; 46(3):333-7. PMID: 9317795

8. Pavana P, Sethupathy S, Manoharan S. Antihyperglycemic and antilipidperoxidative effects ofTephrosia purpurea seed extract in streptozotocin induced diabetic rats. Indian J Clin Biochem. 2007; 22(1):77-83. PMID: 23105657

9. Gallou G, Ruelland A, Legras B, Maugendre D, Allannic H, Cloarec L. Plasma malondialdehyde in type 1 and type 2 diabetic patients. Clin Chim Acta. 1993; 214(2):227-34. PMID: 8472388

10. Kim HK, Kim MJ, Cho HY, Kim EK, Shin DH. Antioxidative and anti-diabetic effects of amaranth (Amaranthus esculantus) in streptozotocin-induced diabetic rats. Cell Biochem Funct. 2006; 24(3):195-9. PMID: 16634092

11. McGarry JD. Banting lecture 2001: dysregulation of fatty acid metabolism in the etiology of type 2 diabetes. Diabetes. 2002; 51(1):7-18. PMID: 11756317

12 Nishikawa T, Araki E. Mechanism-based antioxidant therapies promise to prevent diabetic complications? J Diabetes Investig. 2013; 4(2):105-7. PMID: 24843640

13. Poitout V, Robertson RP. Minireview: Secondary beta-cell failure in type 2 diabetes--a convergence of glucotoxicity and lipotoxicity. Endocrinology. 2002; 143(2):339-42. PMID: 11796484

14. Li N, Ragheb K, Lawler G, Sturgis J, Rajwa B, Melendez JA, et al. Mitochondrial complex I inhibitor rotenone induces apoptosis through enhancing mitochondrial reactive oxygen species 
production. J Biol Chem. 2003; 278(10):8516-25. PMID: 12496265

15. Marin DP, Bolin AP, Macedo Rde C, Sampaio SC, Otton R. ROS production in neutrophils from alloxan-induced diabetic rats treated in vivo with astaxanthin. Int Immunopharmacol. 2011; 11(1):103-9. PMID: 21055504

16. Rossoni-Junior JV, Araujo GR, Padua Bda C, Chaves MM, Pedrosa ML, Silva ME, et al. Annato extract and beta-carotene modulate the production of reactive oxygen species/nitric oxide in neutrophils from diabetic rats. J Clin Biochem Nutr. 2012; 50(3):177-83. PMID: 22573917

17. Meghana K, Sanjeev G, Ramesh B. Curcumin prevents streptozotocin-induced islet damage by scavenging free radicals: a prophylactic and protective role. Eur J Pharmacol. 2007; 577(13):183-91. PMID: 17900558

18. Kim EK, Kwon KB, Song MY, Seo SW, Park SJ, Ka SO, et al Genistein protects pancreatic beta cells against cytokine-mediated toxicity. Mol Cell Endocrinol. 2007; 278(1-2):18-28. PMID: 17881116

19. Matkowski A, Piotrowska M. Antioxidant and free radical scavenging activities of some medicinal plants from the Lamiaceae. Fitoterapia. 2006; 77(5):346-53. PMID: 16713687

20. Paduch R, Matysik G, Wójciak-Kosior M, Kandefer-Szerszen M, Skalska-Kaminska A, Nowak-Kryska M, et al. Lamium album extracts express free radical scavenging and cytotoxic activities. Pol J Environ Stud. 2008; 17(4):569-80.

21. YALÇIN FN, Kaya D, Çaliş İ, Ersoez T, Palaska E. Determination of iridoid glycosides from four Turkish Lamium species by HPLC-ESI/MS. Turk J Chem. 2008;32(4):457-67.

22. Yalçın FN, Kaya D, Kılıç E, Özalp M, Ersöz T, Çalış İ. Antimicrobial and free radical scavenging activities of some Lamium species from Turkey. Hacettepe Univ Fac Pharm. 2007:27,111-22.

23. Lee JJ, Yi HY, Yang JW, Shin JS, Kwon JH, Kim CW. Characterization of streptozotocin-induced diabetic rats and pharmacodynamics of insulin formulations. Biosci Biotechnol Biochem. 2003; 67(11):2396-401. PMID: 14646199

24. Mehran MM, Norasfard MR, Abedinzade M, Khanaki K. Lamium album or Urtica dioica?Which is more effective in decreasing serum glucose, lipid and hepatic enzymes in streptozotocin induced diabetic rats: a comparative study. Afr J Tradit Complement Altern Med. 2015; 12(5).

25. Wolfe K, Wu X, Liu RH. Antioxidant activity of apple peels. J Agric Food Chem. 2003; 51(3):609-14. PMID: 12537430

26. Ordonez A, Gomez J, Vattuone M. Antioxidant activities of Sechium edule (Jacq.) Swartz extracts. Food chem. 2006; 97(3):452-8.

27. Basha MP, Saumya S. Influence of fluoride on streptozotocin induced diabetic nephrotoxicity in mice: Protective role of Asian ginseng (Panax ginseng) \& banaba (Lagerstroemia speciosa) on mitochondrial oxidative stress. Indian J Med Res. 2013; 137(2):370. PMID: 23563382
28. Sellamuthu PS, Arulselvan P, Kamalraj S, Fakurazi S, Kandasamy M. Protective nature of mangiferin on oxidative stress and antioxidant status in tissues of streptozotocin-induced diabetic rats. ISRN Pharmacol. 2013; 2013:750109. PMID: 24167738

29. Rose NR, Conway de Macario E, Folds JD, Lane HC, Nakamura RM(ed). Manual of Clinical Laboratory Immunology, 5th ed. Washington, DC: ASM Press; 1997. 861-2.

30. Guerra JF, Magalhaes CL, Costa DC, Silva ME, Pedrosa ML. Dietary acai modulates ROS production by neutrophils and gene expression of liver antioxidant enzymes in rats. J Clin Biochem Nutr. 2011; 49(3):188-94. PMID: 22128218

31. Masella R, Di Benedetto R, Vari R, Filesi C, Giovannini C. Novel mechanisms of natural antioxidant compounds in biological systems: involvement of glutathione and glutathione-related enzymes. J Nutr Biochem. 2005; 16(10):577-86. PMID: 16111877

32. Rinaldi M, Moroni P, Paape MJ, Bannerman DD. Evaluation of assays for the measurement of bovine neutrophil reactive oxygen species. Vet Immunol Immunopathol. 2007; 115(1-2):107-25. PMID: 17067684

33. Fay AJ, Qian X, Jan YN, Jan LY. SK channels mediate NADPH oxidase-independent reactive oxygen species production and apoptosis in granulocytes. Proc Natl Acad Sci U S A. 2006; 103(46):17548-53. PMID: 17085590

34. Nakanishi S, Suzuki G, Kusunoki Y, Yamane K, Egusa G, Kohno N. Increasing of oxidative stress from mitochondria in type 2 diabetic patients. Diabetes Metab Res Rev. 2004; 20(5):399-404. PMID: 15343586

35. Inoguchi T, Li P, Umeda F, Yu HY, Kakimoto M, Imamura M, et al. High glucose level and free fatty acid stimulate reactive oxygen species production through protein kinase C-dependent activation of $\mathrm{NAD}(\mathrm{P}) \mathrm{H}$ oxidase in cultured vascular cells. Diabetes. 2000; 49(11):1939-45. PMID: 11078463

36. Tuttle KR, Anderberg RJ, Cooney SK, Meek RL. Oxidative stress mediates protein kinase $\mathrm{C}$ activation and advanced glycation end product formation in a mesangial cell model of diabetes and high protein diet. Am J Nephrol. 2009; 29(3):171-80. PMID: 18781061

37. Pereira OR, Macias RI, Perez MJ, Marin JJ, Cardoso SM. Protective effects of phenolic constituents from Cytisus multiflorus, Lamium album L. and Thymus citriodorus on liver cells. J Funct Foods. 2013; 5(3):1170-9.

38. Gabriel H, Schwarz L, Born P, Kindermann W. Differential mobilization of leucocyte and lymphocyte subpopulations into the circulation during endurance exercise. Eur J Appl Physiol Occup Physiol .1992; 65(6):529-34. PMID: 1483441

39. McCarthy DA, Macdonald I, Grant M, Marbut M, Watling M, Nicholson S, et al. Studies on the immediate and delayed leucocytosis elicited by brief (30-min) strenuous exercise. Eur J Appl Physiol Occup Physiol. 1992; 64(6):513-7. PMID: 1618188 